\title{
ENGAGEMENT ACADÊMICO NO ENSINO SUPERIOR: PREMISSA PEDAGÓGICA PARA O DESENVOLVIMENTO DE COMPETÊNCIAS TRANSFERÍVEIS
}

\author{
ROSA MARIA RIGO ${ }^{1 ; *}$ \\ ORCID: https://orcid.org/0000-0001-8266-1969 \\ JOSÉ ANTÓNIO MARQUES MOREIRA ${ }^{2 ; * *}$ \\ ORCID: https://orcid.org/0000-0003-0147-0592 \\ MARIA INÊS CÔRTE VITÓRIA ${ }^{1 ; * * *}$ \\ ORCID: https://orcid.org/0000-0001-6450-429X
}

\begin{abstract}
RESUMO: Em tempos de ciber espaços de aprendizagem, os sistemas de educação necessitam de modelos pedagógicos que possibilitem aos estudantes engajar-se, desenvolver competências e sentiremse aptos a transferir essas competências para outros contextos de atuação. É pois, a partir do modelo pedagógico utilizado pela Universidade Aberta de Portugal, e, baseado na metodologia de Design Based Research com análise qualitativa das percepções dos estudantes envolvidos, que pretendemos neste estudo, analisar se a disciplina Ambientes Virtuais de Aprendizagem promoveu o desenvolvimento de competências transferíveis. Os resultados apontaram posicionamentos positivos como: 1) proporcionou debates envolvendo questões educativas relacionadas com aspectos sociais, políticos ou filosóficos; 2) possibilitou convivência em uma comunidade de prática com experiências e pontos de vista diferenciados; 3 ) alternativas criativas para melhorar práticas pedagógicas e formativas; 4) soluções para problemas complexos 5) promoveu engagement com significado. São discutidas as implicações dos resultados encontrados, tanto do ponto de vista de intervenção prática, quer em termos de investigações futuras.
\end{abstract}

Palavras-chave: engagement acadêmico, competências e habilidades, ensino superior.

\section{ACADEMIC ENGAGEMENT IN HIGHER EDUCATION: PEDAGOGICAL PREMISES FOR THE DEVELOPMENT OF TRANSFERABLE SKILLS}

\footnotetext{
${ }^{1}$ Pontifícia Universidade Católica do Rio Grande do Sul/PUCRS. Porto Alegre, RS, Brasil.

* Doutora em Educação. <rosa.rigo01@gmail.com>

${ }^{2}$ Universidade Aberta de Portugal. Lisboa, Portugal.

**Doutor em Ciências da Educação.<jmoreira@uab.pt>

***Doutora em Educação. <mvitoria@pucrs.br>
} 


\begin{abstract}
In times of cyber learning spaces, education systems need pedagogical models that enable students to engage, develop skills, and feel capable to transfer them to other contexts. Based on the Design Based Research methodology of qualitative analysis of student's perceptions, we analyzed whether the Virtual Learning Environments discipline promoted the development of transferable skills. The findings regarding the class were primarily positive, such as it: 1) promoted debates involving educational issues related to social, political or philosophical aspects; 2) enabled coexistence in a community with different experiences and points of view; 3) created alternatives to improve pedagogical and formative practices; 4) provided solutions to complex problems; and 5) promoted meaningful engagement. The implications of the results are discussed, both from the point of view of practical intervention and in terms of future research.
\end{abstract}

Keywords: academic engagement, skills and abilities, higher education.

\title{
COMPROMISO ACADÉMICO EN LA EDUCACIÓN SUPERIOR: LOCALES PEDAGÓGICOS PARA EL DESARROLLO DE HABILIDADES TRANSFERIBLES
}

RESÚMEN: En tiempos de ciber espacios de aprendizaje, los sistemas de educación necesitan modelos pedagógicos que posibiliten a los estudiantes comprometerse, desarrollar competencias y sentirse aptos para transferir esas competencias a otros contextos de actuación. Por lo tanto, es a partir del modelo de enseñanza utilizada por la Universidad Abierta de Portugal, y, en base a la metodología de Diseño de la investigación basada en un análisis cualitativo de las percepciones de los estudiantes involucrados, queremos que este estudio para analizar si la entornos virtuales de aprendizaje disciplina promovió el desarrollo de competencias transferibles. Los resultados apunta a posicionamientos positivos como: 1) proporcionó debates involucrando cuestiones educativas relacionadas con aspectos sociales, políticos o filosóficos; 2) posibilitó convivencia en una comunidad de práctica con experiencias y puntos de vista diferenciados; 3) alternativas creativas para mejorar prácticas pedagógicas y formativas; 4) soluciones para problemas complejos 5) promovió engagement con significado. Se discuten las implicaciones de los resultados, tanto desde el punto de vista de la intervención práctica como con vistas a futura investigación.

Palabras clave: engagement académico, competencias y habilidades, enseñanza superior.

\section{INTRODUÇÃO}

Expectativas mundiais prospectam para o século XXI a necessidade de se desenvolver novas competências de modo a criar valor e empreender respostas mais compensatórias e autônomas, na vida pessoal, social e profissional. Estas competências encontram-se publicadas em documentos como Educacion 2030 (UNESCO, 2015) The Future of Education and Skills 2030 (OECD, 2018) Organisation for Economic Co-operation and Development ou no documento publicado pelo World Economic Forum New Visions for Education: Unlocking the Potencial of Technology (2015). ${ }^{3}$ Esse chamamento internacional visa também encontrar alternativas para garantir que os sistemas educacionais tenham o capital humano engajado e preparado para realizar essa importante missão.

Embora a terminologia seja diferente ou interpretada de diferentes modos entre os distintos países, a composição enfatizada envolve, conhecimentos, competências e valores ou qualidades de carácter. Ao transpormos este conjunto de características que o cidadão deste século deve possuir para o campo da prática educativa, essas ideações se consolidam em dezasseis competências que o mercado de trabalho exige, e, que portanto, os alunos precisam desenvolver para atuar no século XXI (WEF, 2015). Ainda de acordo com o WEF, estas competências foram categorizadas em três eixos temáticos a saber: 1) Literacias fundacionais; 2) Competências-chave; e 3) Qualidades de caráter. Juntas, elas explicitam as qualidades de caráter, as competências, e as literacias essenciais para o desenvolvimento de tarefas diárias, para o

\footnotetext{
${ }^{3}$ Disponível em http://www3.weforum.org/docs/WEFUSA_NewVisionforEducation_Report2015.pdf
} Educação em Revista|Belo Horizonte|v.36|e217239|2020 
enfrentamento de desafios complexos e suas consequentes mudanças. Os eixos descrevem as competências a desenvolver:

\section{QUADRO 1. Competências para o século XXI}
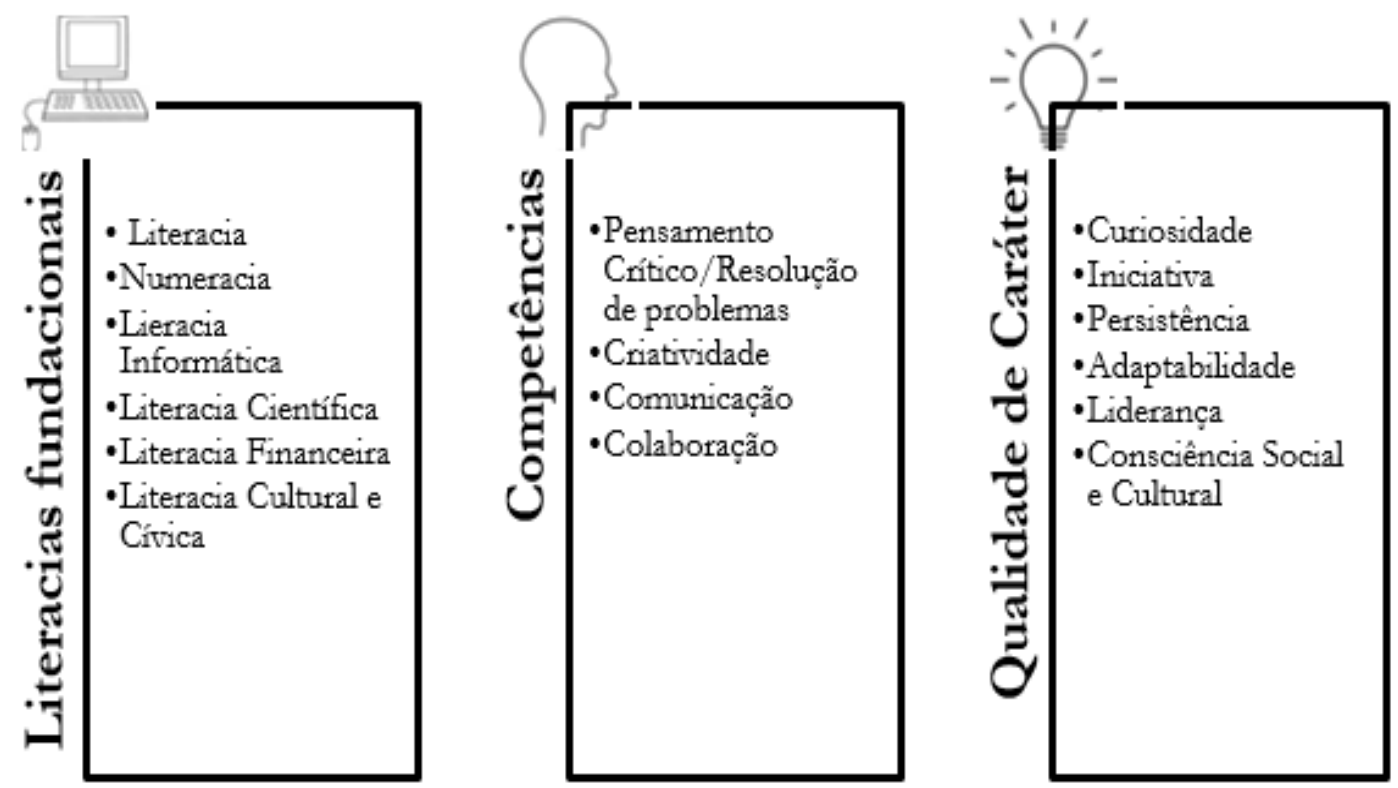

Fonte: traduzido e adaptado de WEF (World Economic Forum, 2015)

As Literacias Fundacionais, ou competências para aplicar os saberes adquiridos, referem-se às competências fundamentais na resolução de tarefas do quotidiano. Estas competências servem de base a partir das quais os estudantes conseguem construir outras competências e qualidades de caráter mais avançadas, mas igualmente importantes. Este eixo inclui não só as competências de literacia e cálculo, mas também a literacia científica, a literacia informática, a literacia financeira e a literacia cultural e cívica. A aquisição destas competências tem sido o foco tradicional da educação à volta do mundo. Historicamente, ser capaz de compreender textos escritos e relações quantitativas tem sido suficiente para entrar no mundo do trabalho. Agora, e de acordo com o documento, estas competências representam apenas o ponto de partida do caminho para a mestria das competências do século XXI.

As Competências-chave, ou capacidades para abordar os desafios complexos em que vão intervir, referem-se à forma como os alunos vão lidar com a complexidade desses desafios. Incluem o pensamento crítico, referindo-se à capacidade para identificar, analisar e avaliar diferentes situações, ideias e informações, por forma a formular respostas a problemas; a criatividade como a capacidade para imaginar estratégias inovadoras para abordar determinados problemas, responder a questões ou conseguir expressar um determinado sentido quando aplicam, ou reorganizam conhecimentos; e a comunicação e colaboração como a capacidade de trabalhar em coordenação com outros para reunir a informação necessária à resolução de problemas.

$\mathrm{E}$ as Qualidades de Caráter, que expressam a relação com o meio envolvente, referem-se à forma como os alunos abordam o seu ambiente em transformação. Entre mercados que mudam de forma tão rápida, qualidades de caráter tais como, a persistência e a adaptabilidade asseguram maior resiliência e sucesso perante o aparecimento de obstáculos. Por outro lado, a curiosidade e a iniciativa, servem de pontos de partida para descobrir novos conceitos e ideias. E, por sua vez, a liderança e consciência social e cultural envolvem interações construtivas com outros de forma social, ética e culturalmente apropriadas.

Também, nesta linha de pensamento, Tony Wagner (2008), fundador do Change Leadership Group da Harvard Graduate School of Education, acredita que os alunos precisam de desenvolver sete habilidades de sobrevivência para estarem preparados para a vida, para o trabalho e para a cidadania do século 
XXI. São elas: (1) pensamento crítico e resolução de problemas; (2) colaboração e liderança; (3) agilidade e adaptabilidade; (4) iniciativa e empreendedorismo; (5) comunicaşão oral e escrita eficaz; (6) acessar e analisar informações; (7) curiosidade e imaginação.

Por sua vez, o Consórcio Century Skills (2008), grupo de países que inclui Austrália, Finlândia, Portugal, Singapura, o Reino Unido e os Estados Unidos, organiza essas competências em quatro categorias: 1)Formas de pensar: criatividade e inovação, pensamento crítico, resolução de problemas, tomada de decisão e aprender a aprender (ou metacognição); 2) Formas de trabalhar: comunicação e trabalho em equipe; 3) Ferramentas para o trabalho: conhecimento geral e tecnologia de comunicação de informação (TIC) alfabetização; 4) Viver no mundo: cidadania, vida e carreira, responsabilidade pessoal e social, incluindo consciência e competência cultural.

Finalmente, Saavedra e Opfer (2012, p. 1) sugere nove princípios para ensinar essas habilidades: (1) tornar a aprendizagem relevante para o quadro geral; (2) ensinar através das disciplinas; (3) desenvolver e ordenar habilidades de pensamento para incentivar a compreensão em diferentes contextos; (4) incentivar a transferência de aprendizagem; (5) ensinar como aprender a aprender ou metacognição; (6) abordar os mal-entendidos diretamente; (7) promover trabalho em equipe; (8) explorar a tecnologia para apoiar a aprendizagem; e (9) fomentar a criatividade dos alunos.

Contudo, embora muitas destas competências tenham sido elaboradas recentemente (WEF, 2015), algumas delas, ainda estão em fase de avaliação por parte das instituições educativas. Por tais prerrogativas, e, de acordo com as palavras de Fullan e Langworthy (2013), muitas ainda precisamos passar da fase das definições para a fase de implementação; portanto, é preciso ainda, clarificar como os professores podem desenvolver práticas pedagógicas que levem a futuros mais bem-sucedidos para todos os alunos. E, diante desse fascinante desafio, estamos convivendo com novos e estimulantes modos de aprendizado, sobretudo de interação entre a pedagogia e tecnologia (FULLAN; LANGWORTHI, 2013). Contudo, apesar da ausência de algumas definições mais especificas, uma característica inerente já é de consenso: a necessidade de engagement para tornar isso possível. Nesse sentido o engagement de alunos, professores e equipes é fundamental. Engagement entendido, em contexto educacional, para descrever os comportamentos e atitudes considerados fundamentais para uma experiência de aprendizado envolvendo tempo, energia e recursos que os estudantes dedicam às atividades para melhorar sua aprendizagem. Nessa perspetiva, pensar em engajar os alunos é trabalhar para atrai-los, inspirá-los, apoiá-los e capacitálos a aprender, é dar-lhes as oportunidades para se desenvolverem com maior autonomia (TROWLER, 2010).

Diante de tais expectativas, os alunos precisam aprender como e por que é fundamental serem cidadãos engajados, cidadãos ativos para conseguir desenvolver capacidades, resolver problemas de vida real, propor ou revisar políticas, enfrentar os desafios sociais, trabalhar com os pares, comunicarse de forma eficaz oralmente e por escrito, compartilhar opiniões publicamente, defender seus direitos, propor novas soluções (SAAVEDRA; OPFER, 2012). Para desenvolver estas e muitas outras competências engajar-se é imprescindível. Nessa seara, engajar-se com propósitos pedagógicos, tem se tornado um grande desafio interdisciplinar, razão pelo qual emerge como premente necessidade, desenvolver competências-chave para o século XXI.

E perante esta realidade as instituições educativas enfrentam, hoje, o desafio não só de criar cenários de aprendizagem que promovam a aquisição de conhecimentos, mas também de cenários para o desenvolvimento de competências de aprendizagem. É precisamente, um desses cenários, que pretendemos analisar, descrevendo o seu impacto no desenvolvimento de competências transferiveis, de estudantes de pós-graduação - Mestrado em Pedagogia do eLearning -, a partir da análise qualitativa das suas percepções e narrativas e tendo como referencial o Modelo Pedagógico Virtual da Universidade Aberta, Portugal. É pois, neste cenário envolvendo o engagement acadêmico como fio condutor para o desenvolvimento de competências transferíveis, que nosso texto pretende transitar.

\section{ENGAGEMENT PARA O DESENVOLVIMENTO DE COMPETÊNCIAS TRANSFERÍVEIS: CONCEPÇÕES TEÓRICAS}

Ao buscarmos aportes teóricos acerca da temática em destaque, encontramos na literatura, inúmeras listas fornecendo inshigts, como os mencionados anteriormente, com sugestões ou alternativas 
de como desenvolver no estudante competências para o século XXI. Para todas as listas apontadas pela literatura, identifica-se a necessidade de engagement por parte dos estudantes, sendo o engagement considerado a chave mestra que abre portas para o desenvolvimento pessoal de competências almejadas para este século. Nessa linha interpretativa, parte-se do pressuposto que, os alunos precisam estar engajados para participar de um processo de aprendizagem dinâmico, gradual e evolutivo ao longo de sua vida. Dada a ampla abrangência do termo, o engagement segundo Kuh e Hu (2001) atendem dois objetivos na Educação Superior: desenvolvimento institucional e desenvolvimento individual. O desenvolvimento institucional avalia como os recursos institucionais, cursos e outras oportunidades de aprendizagem facilitam a participação dos estudantes em atividades que são importantes para a aprendizagem, e o desenvolvimento individual avalia a quantidade de tempo e esforço que estes investem em seus estudos e em outras atividades educacionais. Em linhas gerais, trata-se de um processo envolvendo a compreensão de diversos fatores: a) como se produzem os processos de ensino e aprendizagem na Universidade; b) fatores que mais influenciam para aprendizados e resultados mais significativos; c) quantidade de energia física e psicológica dedicada à experiência acadêmica; d) nível de aprendizagem condicionado ao nível de motivação, nível de implicação (motivação, tempo e energia) que se aplicam ao processo de aprender na Educação Superior.

Os estudos de McCormick e Kinzie (2018) acrescentam ainda que, mapear o engagement dos estudantes pode ser uma valiosa ferramenta de avaliação para universidades, no sentido de acompanhar o sucesso de suas práticas acadêmicas. Nesta linha interpretativa, significa dizer, que boas práticas pedagógicas devem encorajar o contato entre estudantes e professores, a cooperação entre estudantes e uma aprendizagem ativa. Estudos correlacionados comprovam que os estudantes se engajam mais quando as práticas pedagógicas proporcionam: 1) desafio acadêmico; 2) aprendizagem ativa e colaborativa; 3) interação com os pares; 4) enriquecimento de experiências; e 5) ambientes de apoio (SMITH et.al., 2013).

A partir de tais pressupostos, este conjunto de competências quando desenvolvidas, refletem objetivamente em novos saberes aliando-se aos já existentes, nutrindo a criatividade, a originalidade, estabelecendo novos hábitos cognitivos, novas formas de adquirir conhecimento, bem como transferir esses conhecimentos. Quando desenvolvidos em cooperação este saberes potencializam-se, agregando os saberes dos pares aos já existentes, de modo que, as ideias recém-chegadas, passam a aliar-se a novas reações ou insights para o grupo, e, a junção destes por sua vez, podem produzir novos insights, com novas possibilidades para reverter-se em alternativas eficazes para a compreensão de conceitos mais difíceis ou mais complexos, por exemplo.

Por seu curso, o incentivo à transferência de aprendizados pode ser interpretado quando os alunos conseguem aplicar os conhecimentos e competências que adquirem em uma determinada disciplina para outra, ou para outros contextos, quer sociais, quer profissionais. Contudo, por se tratar de estudantes do ensino superior, confere-se particular importância à valorização e à transferência de conhecimentos para a sociedade, uma postura que se espera em final de formação, qual seja - estarem aptos para responder as necessidades da sociedade, apresentando a resolução de problemas. Portanto, a identificação de sinergias entre "o que se aprende e o que se consegue transferir" é um dos motes que permeia a sociedade do conhecimento, razão pela qual "espera-se", dos estudantes, que consigam prosperar diante dessa nova missão. Contudo, esta aplicação - ou transferência de saberes - pode se constituir para alguns, em um imenso desafio mais difícil de suplantar.

Estudos desenvolvidos por Saavedra e Opfer (2012) acreditam que a transferência de competências envolve três questionamentos distintos: 1. Quais habilidades, conceitos, conhecimentos, atitudes e estratégias podem ser transferidos? 2. Para qual contexto, situação ou aplicativo? 3. Como a transferência pode ocorrer? Os autores acreditam que, para responder a tais questões algumas alternativas podem incluir: a capacidade de trabalhar em equipe; o envolvimento com o aprendizado, a compreensão de causa e efeito; a resolução de problemas através de tentativa e erro; e a transferência para outros cursos ou para futuros ambientes de trabalho. Sendo que a transferência pode ocorrer de duas maneiras: 1) reflexivamente aplicando o que sabem, ou 2) fazendo conexões conceituais entre as leis científicas e situações que eles podem encontrar em suas vidas.

Os autores acrescentam ainda (SAAVEDRA; OPFER, 2012), algumas maneiras mais específicas pelas quais os professores podem incentivar a transferência, utilizando métodos como: 1) Conceber experiências de aprendizagem semelhantes às situações em que os alunos possam precisar de 
aplicar o conhecimento e as habilidades; 2) Estabelecer expectativas dizendo aos alunos que eles precisarão estruturar seus históricos com argumento - ensaio de casa da mesma forma que praticam em sala de aula; 3) Pedir aos alunos que pratiquem debatendo um tópico em particular, em pares, antes de realizar um trabalho em larga escala; 4) Organizar julgamentos simulados, ou outros exercícios de interpretação de papéis como forma de praticarem o engajamento cívico; 5) Conversar com a solução de um problema específico para que entendam pensando no processo, como podem aplicar para um problema semelhante; 6) Encontrar e usar evidências históricas de uma fonte primária e, em seguida, fazer o mesmo com uma fonte primária diferente. O objetivo de cada uma dessas atividades é desenvolver a familiaridade e conforto com situação de aprendizagem, que é muito semelhante a uma nova situação de aprendizagem para a qual eles precisam transferir habilidades e conceitos (SAAVEDRA; OPFER, 2012).

Outros métodos para incentivar a transferência de saberes complexos podem envolver solicitação de brainstorming sobre as formas em que podem aplicar determinada habilidade; fazer analogias entre um tópico e algo diferente, como entre ecossistemas e mercados financeiros; pensar explicitamente sobre seu próprio pensamento; um processo conhecido como metacognição (SAAVEDRA; OPFER, 2012).

Sinay e Graikinis (2018), pesquisadores do Toronto School Board (TDSB), acreditam que, para ocorrer a produção de conhecimento transferível um conjunto de abordagens instrucionais deve estar alinhado a três fundamentos básicos de aprendizado: 1)envolvido com significado; 2) conhecimento factual organizado em torno de um quadro conceitual; e 3) ambiente de aprendizagem usando práticas metacognitivas, envolvendo um aprendizado mais profundo. Este aprendizado profundo, para Mehta e Fine (2015, p.4) emerge na encruzilhada do domínio do conteúdo, motivação intrínseca (identidade) e ação ou criação de algo novo dentro do campo (criatividade). A aprendizagem mais profunda está associada à "capacidade de transferir conhecimento". A ideia aqui é que o conhecimento torna-se mais profundo quando se pode usá-lo não só para abordar um problema no contexto em que foi ensinado, mas também para entender ou explicar algo em um contexto diferente, porém relacionado. Contudo, para transferir conhecimentos que levem a ações concretas, as ofertas pedagógicas precisam oferecer ambientes de aprendizagem autênticos que estimulem o engajamento proposital e significativo e o domínio do conhecimento transferível. Engajar-se como propósito nesse contexto, vem se tornando um dos maiores diferenciais competitivos da atualidade, e um dos maiores desafios interdisciplinares para professores e instituições de ensino, razão pelo qual, estes ambientes de aprendizagem devem cultivar uma série de conhecimentos, valores e atitudes também rotuladas como competências-chave ou globais. Estas atitudes podem ser desencadeadas a partir da utilização de elementos e ferramentas tecnológicas, visando cativar e promover o engajamento necessário.

Em síntese, para que a transferência de competências possa ocorrer (UNESCO 2015), os indivíduos precisam aplicar um novo aprendizado, e desenvolver novas competências em diferentes situações e contextos, onde a avaliação formativa ajuda os professores a estabelecer se os alunos individualmente tiveram experiência para integrar e transferir novos conhecimentos. Por esta razão Fullan e Langworthy (2013) acreditam que o desafio para os sistemas de educação e as novas pedagogias seja, como promover essas oportunidades de aprendizagem de forma conectada e muitas vezes habilitadas pela tecnologia, e como fazê-lo equitativamente em sistemas inteiros.

\section{METODOLOGIA}

Para este estudo optamos por utilizar a metodologia conhecida como Design-Based Research (DBR). Segundo Moreira (2015), trata-se de uma metodologia que procura pesquisar problemas educativos em contextos reais de atuação pedagógica, com vista à resolução de problemas significativos e práticos, conciliando teoria e prática através de uma ligação colaborativa entre investigadores e profissionais que procuram entender, documentar, interpretar e melhorar a prática educativa.

Essa metodologia ganha adesão, por buscar investigar estudos que utilizam as tecnologias com propósito de inovação e desenvolvimento de práticas pedagógicas consistentes para ambientes digitais. De acordo com Barab e Squire (2004) esta metodologia adota uma série de procedimentos de 
investigação aplicados para o desenvolvimento de teorias, artefatos e práticas pedagógicas com potencial aplicação e utilidade em processos de ensino-aprendizagem existentes.

Desse modo, como alternativa para o levantamento de dados utilizou-se um módulo contendo cinco questões elaboradas pela American Association of State Colleges ${ }^{4}$. Cabe explicitar que o referido módulo e respectivas questões, faz parte de uma ampla pesquisa desenvolvida pela NSSE (NATIONAL SURVEY OF STUDENT ENGAGEMENT, 2017), desenvolvida pelo Center for Post Secondary Research Indiana University School of Education para avaliar o engagement dos estudantes. As cinco questões do módulo selecionado, foram adaptadas, visando atender o contexto da unidade curricular e os objetivos deste estudo, nomeadamente se a unidade curricular proporcionou a partir do engagement dos estudantes, o desenvolvimento de competências transferíveis. Após readequadas, as questões foram disponibilizadas através da plataforma Google Drive, com o seguinte enunciado: Durante o decurso da Unidade Curricular - Ambientes Virtuais de Aprendizagem você...

1) Discutiu ou debateu questões educativas relacionadas com aspectos sociais, politicos on filosóficos?

2)Trabalhou numa comunidade de prática com membros com experiências e pontos de vista diferenciados?

3) Pensou criativamente em novas ideias ou em maneiras de melhorar a realidade das suas práticas pedagógicas e formativas?

4) Avaliou criticamente várias soluções para um problema?

5) Discutiu problemas complexos com a comunidade de prática para encontrarem soluções para esses problemas?

\section{ECOSSISTEMA DIGITAL DE APRENDIZAGEM DA UNIDADE CURRICULAR AMBIENTES VIRTUAIS DE APRENDIZAGEM}

A unidade curricular Ambientes Virtuais de Aprendizagem faz parte da estrutura curricular do Curso de Mestrado em Pedagogia do eLearning do Departamento de Educação e Ensino a Distância da Universidade Aberta, sendo que o ecossistema digital de aprendizagem desenvolvido para a sua lecionação é suportado, tecnologicamente, pela plataforma digital institucional -Moodle 2.0-, e outros ambientes e artefatos digitais da web 2.0 e, pedagogicamente, pelo seu modelo pedagógico virtual, que se baseia nos princípios do ensino centrado no estudante, baseado na flexibilidade de acesso à aprendizagem, na interaşão diversificada quer entre estudante-professor quer entre estudante-estudante, quer, ainda, entre o estudante e os recursos e num ensino promotor de inclusão digital (PEREIRA et al., 2007).

Desse modo, com base em princípios pedagógicos definidos pelo modelo virtual de aprendizagem da Universidade Aberta, foi desenvolvido a partir da unidade curricular, o delineamento para a composição deste estudo, partindo das percepções e narrativas dos estudantes acerca do tema "Desenvolvimento de Competências transferiveis", estudo que contou com a participação de dez estudantes do curso de Mestrado em Pedagogia do eLearning.

\section{ANÁLISE DOS DADOS E DISCUSSÃO}

Como forma de articular as respostas, e compor um "entendimento ampliado" acerca da temática analisada, apresentamos a seguir, uma síntese com as ideias principais dos formandos envolvidos, analisando as cinco questões individualmente, e posteriormente, uma análise em diálogo com os autores que discorrem sobre a temática das competências transferíveis e do engagement, referenciados anteriormente. Visando manter o anonimato dos participantes, optamos por identificá-los com EST1, EST2, EST3, EST4, e EST5..., avaliando aleatoriamente as respostas narradas no decorrer da pesquisa. Em relação às respostas dos formandos, EST6, EST7, EST8, EST9, EST10, reitera-se que os mesmos, limitaram-se a responder apenas "Sim" a todas as questões formuladas.

\footnotetext{
${ }^{4}$ Disponível em http://nsse.indiana.edu/
} 
FIGURA 1. Percepções relativas à discussão sobre questões educativas

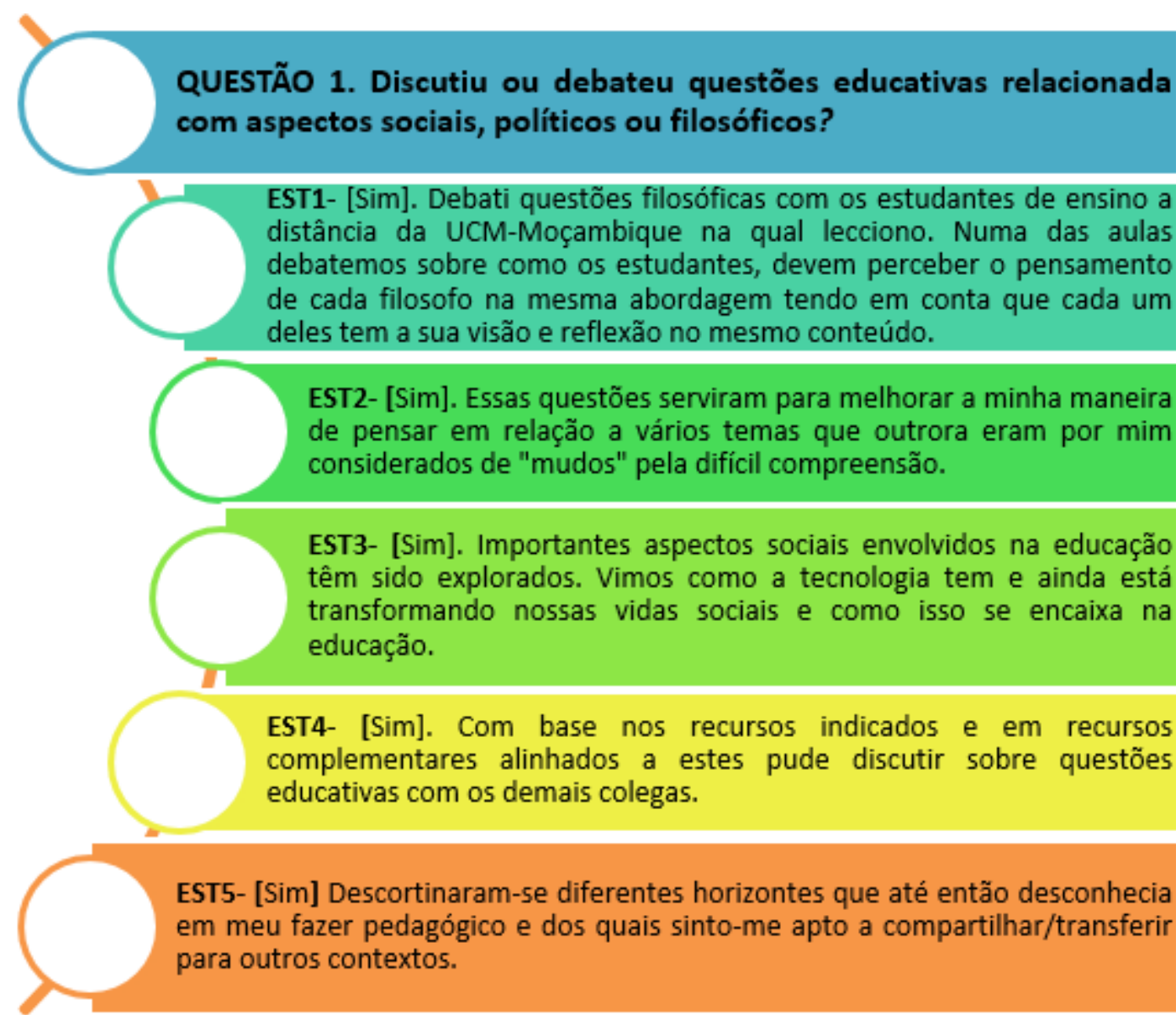

Fonte: elaborada pelos autores

Ao analisarmos as respostas à primeira questão, percebemos que estes formandos, na sua maioria estão "envolvidos com significado" (SINAY; GRAIKINIS, 2018). Uma vez que o aprendizado é integrado às formas de conhecimento existentes, esta alimenta a criatividade e a originalidade e estabelece novos hábitos cognitivos. Denota-se pelas respostas dos formandos (EST1, EST3, EST4 e EST5 ), a relevância e o papel que os ambientes digitais exercem ao trazer contributos essenciais para ampliação e superação dos mais diversos tipos de barreiras, inclusive geográficas, para o descortinar de visões de mundo diferentes, bem como para ampliação de saberes compartilhados com os pares, ou ainda, pela conectividade e interseções entre diferentes nós de informação ou conhecimento que se estendem para além do ambiente de uma sala de aula tradicional. Corroboram com essa linha interpretativa Saavedra e Opfer (2012) ao inferir que as tecnologias com suas recursividades, fornecem aos alunos novas maneiras de resolver seus problemas de forma crítica, de refletir sobre seus pensamentos, bem como avaliar tópicos relevantes para suas vidas usando ferramentas envolventes. No entanto, nem todas as respostas vão no sentido de descrever as sinergias entre "o que aprenderam e o que se conseguem transferir". Denota-se a existência de uma lacuna, ou seja, para a maioria dos estudantes transferir as competências aprendidas, ainda pode se constituir num imenso desafio, se levarmos em conta a ausência de prospecções ou comentários adicionais diante de uma questão prática. Contudo, as aferições de EST2, EST3, EST4 e EST5, se aproximam do pensamento de Mehta e Fine (2015) quando referem que o domínio do conteúdo emerge Educação em Revista|Belo Horizonte|v.36|e217239|2020 
de uma motivação intrínseca (identidade) a partir de uma encruzilhada onde a ação ou a criação de algo novo dentro de um novo campo de ação dependem também de criatividade, ou do desejo de interpretálo e fazê-lo.

FIGURA 2. Percepções relativas à comunidade virtual de prática

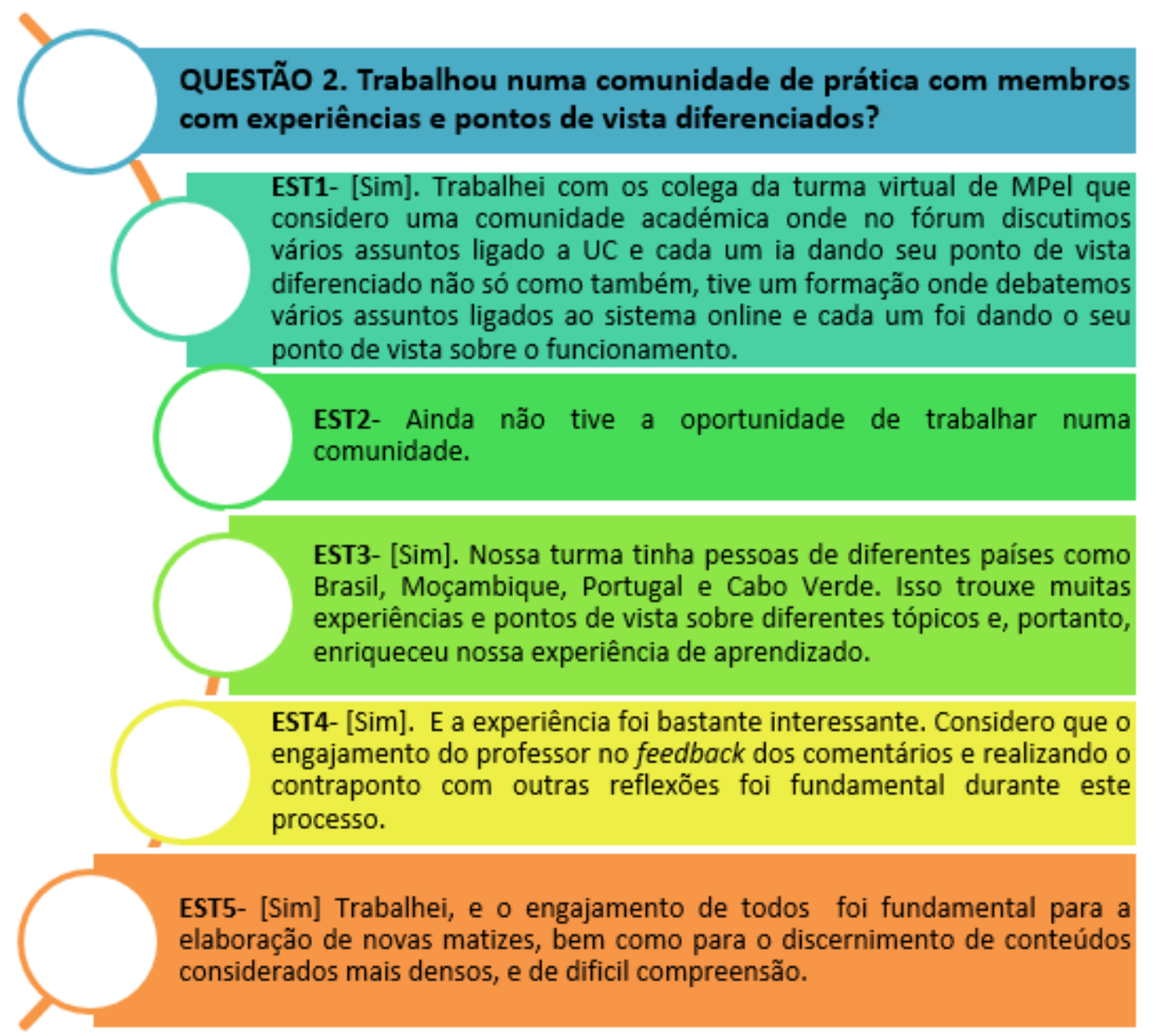

Fonte: elaborada pelos autores

Relativamente à segunda questão relacionada com o desenvolvimento de uma comunidade de prática, a leitura das unidades de registo mostra um número muito elevado de percepções de tendência muito positiva o que indicia, claramente, que os estudantes, consideram que o modelo pedagógico virtual e a metodologia utilizada pelo professor permitiu fortalecer os laços entre os elementos da turma, formando uma comunidade de prática sólida, onde os membros dessa comunidade se exprimiram de forma livre, expondo os seus diferentes pontos de vista (EST1) e incentivados a colaborar e a partilhar informação e conhecimentos, com autonomia, criatividade e de uma forma muito ativa.

Também, o estudante -EST3-, sublinha a facilidade de comunicar neste espaço que permitiu a pluralidade de pontos de vista acerca de um assunto e da interação constante que criou oportunidades de aprendizagem.

Por sua vez o estudante -EST4- considerou muito relevante o papel do docente, na forma como foi direcionando as discussões ou incentivando as participações, promovendo desta forma um ambiente e um espaço verdadeiramente colaborativo de aprendizagem. Este papel de professororientador ou professor-mediador, relaciona-se com uma nova cultura de aprendizagem intrínseco ao 
modelo proposto, que pressupõe que os professores, mais do que transmitir ou ditar informações, devem promover nos seus estudantes, competências de procura, seleção e interpretação da informação disponível, assumindo-se como mediadores e facilitadores (SALMON, 2003).

A maioria dos testemunhos recolhidos sublinha, pois, estas vantagens do ponto de vista do desenvolvimento de competências relacionadas, por exemplo, com a comunicação e a colaboração, com a discussão de ideias e de pontos de vista distintos, preconizada pelo modelo pedagógico virtual da Universidade Aberta.

Nesta linha de pensamento Fullan e Langworthy (2013) defendem que precisamos cada vez mais que os nossos sistemas de aprendizado consigam encorajar os estudantes a desenvolver suas próprias visões sobre o que significa, conectar-se e florescer em um mundo constantemente em mudança, e equipar-se com as interpretações ampliadas de determinados fatos, onde nesse caso, o ponto focal é a busca de "metas de aprendizagem profunda" possibilitadas por novas pedagogias e aceleradas pela tecnologia (FULLAN; LANGWORTHY, 2013, p.8).

Refira-se ainda, que apesar dos restantes estudantes não terem realizado comentários adicionais, todos eles responderam afirmativamente à questão.

\section{FIGURA 3. Percepções relativas ao pensamento crítico}

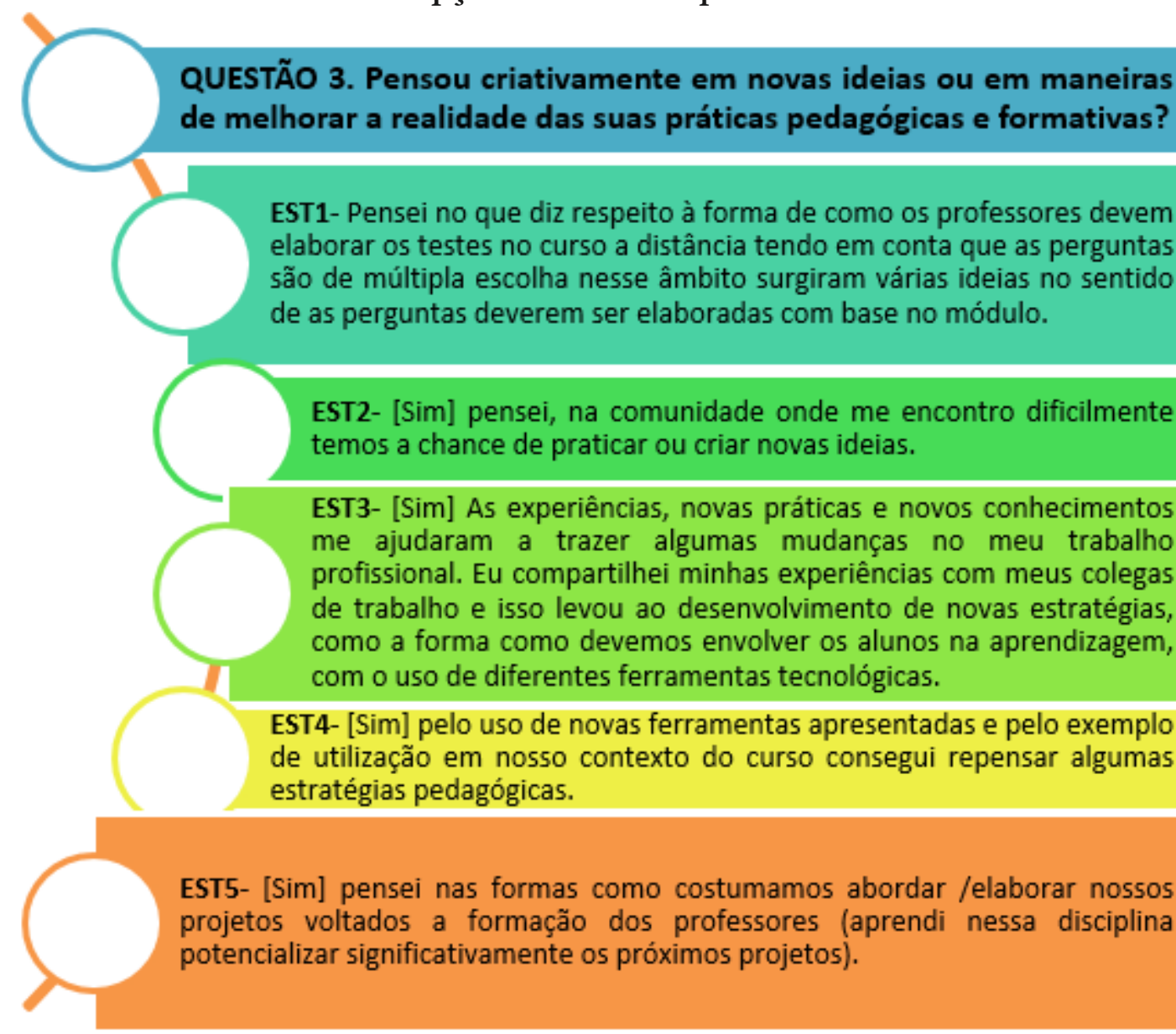

Fonte: Elaborada pelos autores.

O desenvolvimento da criatividade é um dos itens enfatizado para o desenvolvimento das competências do século XXI (WEF, 2015). A criatividade é descrita por Sinay e Graikinis (2018), como a disposição de se engajar em situações para alcançar o desenvolvimento pessoal, de maneira construtiva e reflexiva. Nesse sentido, Saavedra e Opfer (2012) também ressaltam a importância da criatividade para o desenvolvimento na forma de pensar: criatividade e inovação, pensamento crítico, resolução de problemas, tomada de decisão e aprender a aprender (ou metacognição). 
Ao analisarmos as respostas à questão 3 podemos perceber algumas percepções diferenciadas dos formandos, como: forte preocupação com a criatividade para elaboração de conteúdos para contextos de educação a distância (EST1); reflexão criativa em relação ao contexto de atuação profissional (EST2, EST5); e criatividade envolvendo ferramentas pedagógicas utilizadas em contextos pedagógicos (EST4). Estas colocações se aproximam da ideia que Saavedra e Opfer (2012) de que ambientes de aprendizagem que fornecem aos estudantes autodireção, conseguem aumentar a curiosidade, a motivação e consequentemente abrem portas para a criatividade. A reflexão do estudante (EST3) amplia esta possibilidade ao afirmar ter compartilhado suas experiências "com colegas de trabalho, e isso levou ao desenvolvimento de novas estratégias, como a forma como devemos envolver os alunos na aprendizagem, com o uso de diferentes ferramentas tecnológicas", caracterizando o que de fato podemos considerar um exemplo positivo para o desenvolvimento de competências transferiveis, e que foi, a nosso ver, plenamente alcançado na prática.

Por sua vez, segundo Saavedra e Opfer (2012) é possível promover novas ideias ou maneiras de melhorar a realidade das práticas pedagógicas e formativas através do incentivo mediado. O incentivo ajuda os alunos a desenvolver modelos mentais positivos sobre sua capacidade, desenvolver e reconhecer seus próprios processos criativos. Corroboram esta ideia Fullan e Langworthy (2013), ao mencionar que, ensinar sobre o processo criativo é o que anima ou suprime o próprio desenvolvimento criativo individual ao se ressaltar junto aos estudantes a importância da criatividade e da imaginação como fatores de empreendedorismo econômico e social, com ideias inovadoras de liderança para a ações mais profícuas em diferentes campos de atuação, aproximando-se das narrativas dos estudantes (EST1, EST2, EST3, EST4 e EST5).

FIGURA 4. Percepções relativas à criticidade para resolução de problemas

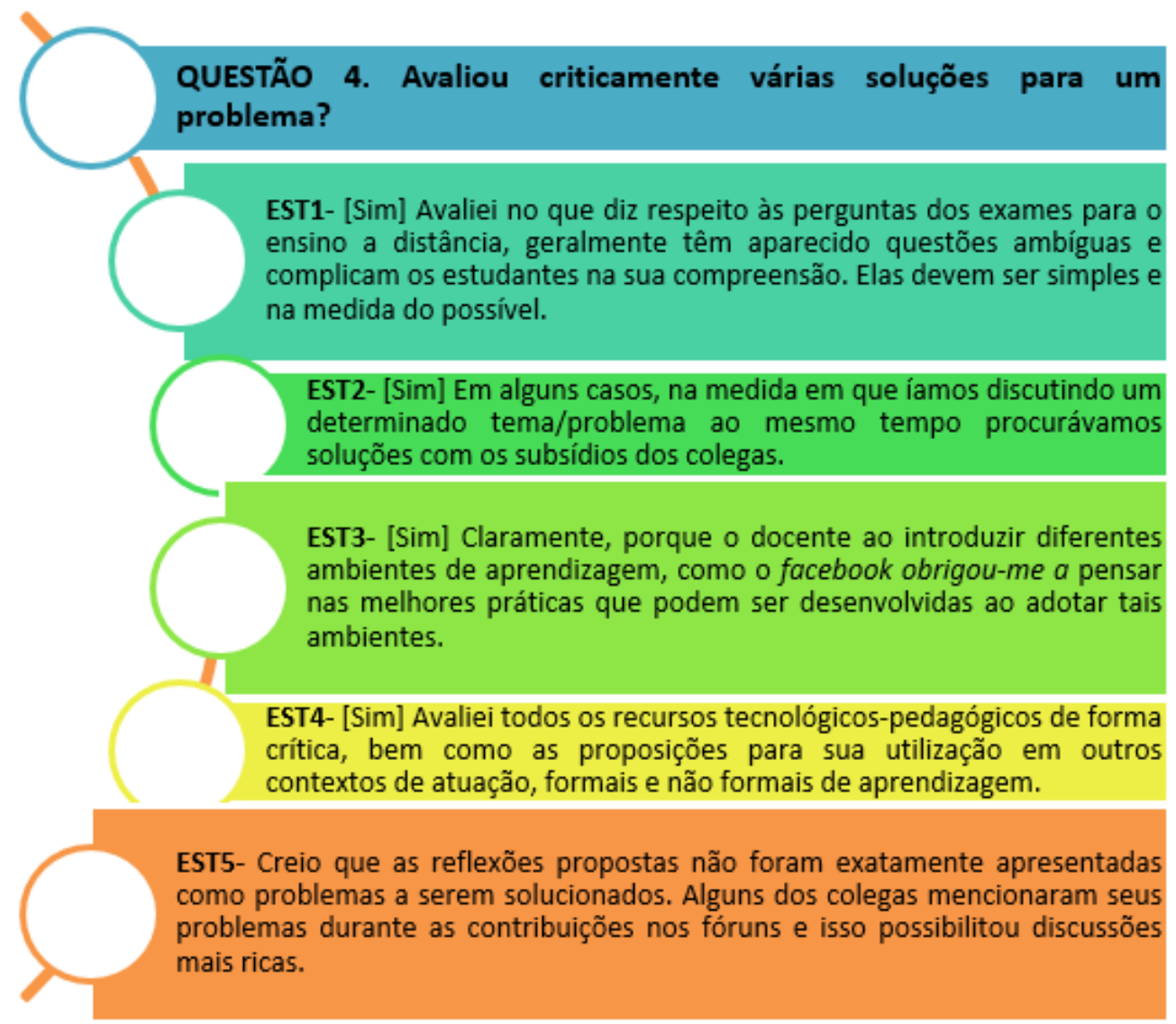

Fonte: Elaborada pelos autores.

Avaliar criticamente pressupõe ter um pensamento crítico na busca de soluções para um determinado problema, ou, pensar criticamente sobre como projetar e gerenciar algo, tomar decisões eficazes usando uma variedade de ferramentas e recursos. Ao avaliarmos as narrativas dos estudantes relativamente à questão 4, percebemos que o docente promoveu uma metodologia ativa de aprendizagem que levou os estudantes a pensar criticamente sobre as questões levantadas, 
quer discutindo essas questões com o professor, quer com os colegas da turma. Com efeito uma leitura atenta das suas declarações, nomeadamente dos estudantes 2 e 5 , que referem a busca de soluções para os problemas levantados com o auxílio dos colegas, permite-nos perceber que a interação que decorreu nas salas de aula virtuais da disciplina, como o Facebook, foi fundamental para o desenvolvimento deste pensamento crítico.

Estas evidências, na opinião de Sinay e Graikinis (2018), entendidas como “processos de pensamento" incluem fazer observações, colocar questões, examinar e rever criticamente as informações disponíveis, propor respostas e fazer previsões. E revelam-se fundamentais para que os estudantes possam fazer uma catálise efetiva das oportunidades de crescimento, levando-os consequentemente a ganhos em competências globais.

FIGURA 5. Percepções relativas à discussão sobre problemas complexos

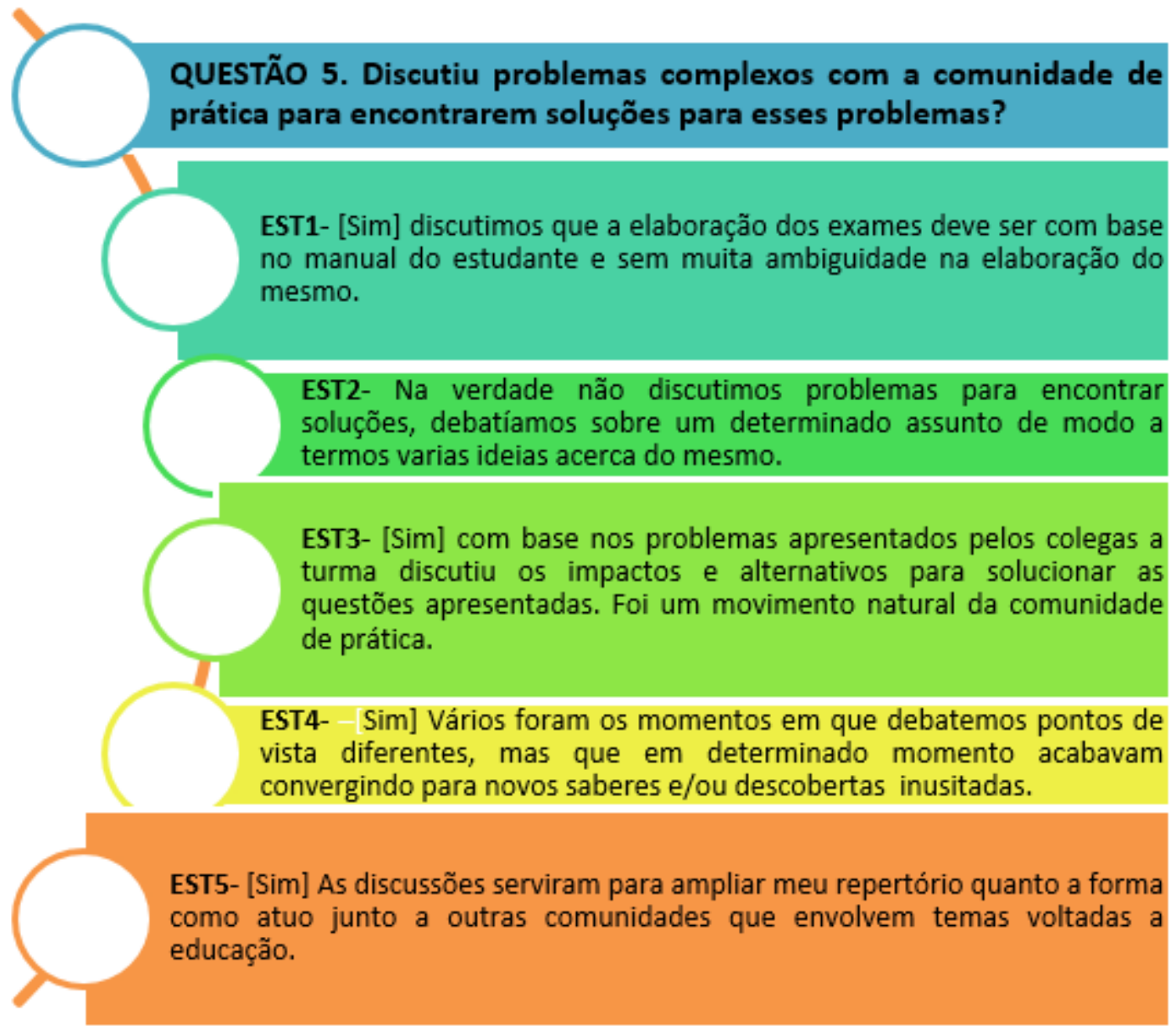

Fonte: Elaborada pelos autores.

Ao analisarmos a questão que encerra este estudo envolvendo a questão do desenvolvimento de competências transferiveis a partir da disciplina Ambientes Virtuais de Aprendiqagem, encontramos nas narrativas dos estudantes (EST3, EST4 e EST5) uma síntese representando um quadro geral da disciplina, onde existiu "um movimento natural da comunidade de prática" e onde foram discutidos "impactos e alternativas" frente às práticas pedagógicas ofertadas. As referidas práticas refletiram o ambiente planejado, mediante a adoção e utilização de um modelo pedagógico virtual que utilizou uma variada gama de tecnologias e plataformas digitais, propiciando aos estudantes: 1) ciclos rápidos de feedback sobre o progresso da aprendizagem através das salas de aula virtuais do Moodle ou do Videoant,2) a utilização de redes sociais como ambientes educacionais, como por exemplo o Facebook ou a OpenRedu;

A busca por soluções compartilhadas entre os pares é ressaltada pelas narrativas (EST1 e EST2), donde se percebe que o modelo pedagógico ofertado contribuiu significativamente para uma Educação em Revista|Belo Horizonte|v.36|e217239|2020 
aprendizagem conectada e florescente, onde o compartilhamento de conhecimentos entre os pares decorreu de forma fluída, agregando valor e significado, alternativa possível de ser adotada por professores e estudantes - uma via de mão dupla, onde, saberes horizontais e em rede, favorecem e potencializam a horizontalidade de papéis destacada por Freire (2000), onde todos podem ensinar e todos podem aprender. Nesses ambientes, o trabalho pode ser baseado em projetos, tendo o desempenho medido pelo impacto das ideias e das habilidades das equipes na execução dessas ideias. Assim, ao ajudar o outro a tomar consciência de si - professor e estudante - ambos se engajam e se conectam em relacionamentos mais profundos de aprendizagem, onde os objetivos pedagógicos podem ser mais facilmente alcançados mediante a identificação e o compartilhamento de exemplos, de projetos ou estratégias de ensino. Ideias similares também são sublinhadas por Fullan e Langworthy (2013), ao ressaltar a importância do engajamento como fator decisivo para encontrar soluções que envolvam a inovação em rede. Como conceito central as questões suscitadas nesta escrita, uma comunidade de prática é aquela que busca discutir a partir de problemas de vida real, encontrando alternativas ou possíveis soluções, desde as mais simples às mais complexas, possibilitando assim, o aprimoramento das competências amplamente destacadas neste estudo.

\section{CONSIDERAÇÕES FINAIS}

Buscar desenvolver capacidades coletivas consiste também em saber promover o engajamento de todos os envolvidos no processo. Desenvolver a sabedoria é atentar aos insights, à intuição e à experiência de todos os intervenientes, no sentido de juntar forças, somando novos saberes aos já existentes, visando adquirir outros conhecimentos e habilidades para consequentemente e naturalmente, poder transferir o que se sabe e domina, a outros contextos. Contudo, sabemos que maximizar o desenvolvimento de processos educativos requer adequações e (re)adequações constantes, objetivando alcançar um ensino de mais qualidade e eficácia. No entanto, o propósito deste estudo não foi o de desafiar os esforços já existentes. O objetivo foi analisar in loco o desenvolvimento (ou não) de competências que possam ser transferíveis a partir do engajamento dos estudantes da disciplina, e, a partir deste refletir sobre a possibilidade de futuras intervenções.

A partir do enunciado, buscamos saber dentre os formandos, se a disciplina - Ambientes Virtuais de Aprendizagem- lhes possibilitou: Discutir ou debater questões educativas relacionadas com aspectos sociais, politicos on filosóficos? As narrativas demonstraram que os estudantes que se engajaram aos conteúdos propostos conseguiram internalizar diferentes significados, integrar e ampliar as formas de conhecimento já existentes, afirmando a intenção de transferir esses conhecimentos para os seus contextos profissionais. Constatou-se ainda que o domínio (ou não) de determinados conteúdos podem associar-se à motivação intrínseca, onde a ação e a criação de algo novo dentro de um campo de ação depende muitas vezes, apenas do desejo de interpretá-lo, fazê-lo. Os resultados deste estudo, prospectam um posicionamento muito favorável em relação à disciplina, oportunizando em certa medida aos participantes da pesquisa, discutir e debater questões educativas relacionada com aspectos sociais, políticos ou filosóficos.

Em relação à questão: Trabalbou numa comunidade de prática com membros com experiências e pontos de vista diferenciados? As respostas obtidas permitiram-nos concluir que o modelo pedagógico virtual e a metodologia utilizada pelo professor permitiu formar uma comunidade de prática sólida, onde os seus membros se exprimiram de forma livre, expondo os seus diferentes pontos de vista e tendo sido incentivados a colaborar e a partilhar informação e conhecimentos, com autonomia, criatividade e de uma forma muito ativa. Para além disso, concluiu-se também que o professor teve um papel importante na formação desta comunidade de prática, tendo criado e orientado discussões estimulantes, facilitando, assim, a construção de um pensamento crítico.

Os resultados para a proposição - Penson criativamente em novas ideias ou em maneiras de melhorar a realidade das suas práticas pedagógicas e formativas? Denotou-se que, o engajamento para alcançar o desenvolvimento pessoal, de maneira construtiva e reflexiva foi fundamental, assim como a criatividade enfatizada sob diferentes aspectos, focos, ou pontos de interesses. Estas características demonstraram um ampliar de possibilidades para o desenvolvimento de saberes compartilhados entre os pares, onde os 
saberes de um estudante, enriqueceu o saber do outro e vice-versa. Para além disso foi interessante perceber que o desenvolvimento desta comunidade de prática permitiu que os estudantes repensassem as suas práticas pedagógicas, e usando a sua criatividade, as alterassem transferindo esses conhecimentos para a sua esfera laboral.

No que concerne ao questionamento - Avaliou criticamente várias soluções para um problema? Os estudantes revelaram em suas narrativas que o professor foi determinante nesta avaliação crítica ao promover metodologias ativas de aprendizagem que os levou a pensar criticamente sobre as questões levantadas, quer discutindo essas questões com o próprio professor, quer com os colegas da turma, tendo sido isso um fator decisivo para o desenvolvimento deste pensamento crítico.

Ao encerrarmos com a questão - Discutiu problemas complexos com a comunidade de prática para encontrarem solucões para esses problemas, identificamos através das narrativas dos estudantes ter existido um processo de maturidade, permeado por um movimento natural da comunidade de prática. Esta disciplina lhes proporcionou, por exemplo, discutir e avaliar impactos e alternativas possíveis para futuras implementações em seus contextos de atuação, a partir das práticas pedagógicas ofertadas/discutidas pela disciplina.

Ao finalizarmos, sem, contudo, encerrar a questão, o presente estudo que buscou analisar o "desenvolvimento de competências transferiveis" apontou, na nossa opinião caminhos e indícios significativos. Embora o estudo não apresente resultados recebidos nos próprios contextos de atuação dos intervenientes quanto às "competências transferiveis" este estudo abriu margem para promissoras reflexões e futuras incursões.

$\mathrm{Na}$ realidade, sendo a perceção das competências um indicador de eficácia, o que valida, em certa medida, modelos e ecossistemas centrados no desenvolvimento de competências, pudemos verificar que, de um modo geral, os estudantes que experienciaram a aprendizagem no espaço de convivência digital analisado, apresentaram uma perceção favorável a nível quer das suas Competências Comunicacionais, quer a nível das Competências de Raciocínio e Resolução de Problemas, referentes à colaboração e trabalho em equipe, à sensibilidade e responsabilidade social, à adaptação e flexibilidade, à criatividade, à autonomia e à iniciativa. E tão, ou mais importante que isso foram revelando que esses conhecimentos adquiridos, resultado de uma pedagogia também direcionada para o desenvolvimento de competências, foram ou irão ser transferidos para os seus contextos sociais e laborais. É consensual que, transferir conhecimentos leva a uma ação: e ações necessitam de engajamento, intencionalidade, autoconhecimento, conectividade, confiança e adaptabilidade, aliadas a motivação intrínseca. Contudo, todas essas características, nem sempre andam juntas em processos de aprendizagem, ou mesmo possam não ser apropriadas para todas as pessoas, ou para momentos específicos. Estas necessitam sobretudo tempo e engagement para que possam florescer, frutificar.

Concluímos enfatizando que, a temática das competências transferíveis requer de nossa parte, novas incursões, o que talvez nos leve de volta ao ponto de partida - a necessidade de se criar mecanismos para a promoção e desenvolvimento dessas competências, ou noutras palavras, entender primeiramente a fundamental lógica idealizada pelos interlocutores acerca do desenvolvimento das competências do século XXI. Apesar da ausência de detalhamento ou mensuração sobre a temática em estudo, buscar aprender como desenvolver estas competências transversais junto aos estudantes tornase fundamental no sentido de atender demandas e expectativas para o contexto global no século XXI.

\section{REFERÊNCIAS}

AMERICAN ASSOCIATION OF STATE COLLEGES,. Disponível em: < http://nsse.indiana.edu/>. Acesso em: 01 de setembro de 2018.

BARAB, S. SQUIRE, K. Design-based research: putting a stake in the ground. Journal of the Learning Sciences, 2004, v. 13, n. 1, p. 1-14. 
FUlLAN, M.; LANGWORTHY, M. Towards a New End: New Pedagogies for Deep Learning. JUNE 2013. Published by Collaborative Impact, Seattle, Washington, USA. Disponível em: <http://www.newpedagogies.nl/images/towards_a_new_end.pdf >. Acesso em: 14 de julho de 2018.

FREIRE, P. Pedagogia da autonomia: saberes necessários à prática educativa. 15. ed. São Paulo: Paz e Terra, 2000.

MEHTA, J.; FINE, S. The why, what, where, and how of deeper learning in American secondary schools. Students at the center: Deeper Learning Research Series. Boston, MA: Jobs for the Future, 2015.

McCORMICK, A; KINZIE, J. Using evidence to promote effective educational practice and the success of all students. Higher Education Policy Conference, Denver, CO., 2018

MOREIRA, J. A. Pedagogia 2.0 na web social e seu impacto no autoconceito de estudantes de PósGraduação. Revista da FAEEBA - Educação e Contemporaneidade, 2015, v. 24, n. 44, p. 83-95, jul./dez. 2015.

KUH, G.; HU, S. Learning productivity at research universities. Journal of Higher Education, 2001, v. 72, n. 1, p. 1-28.

NSSE (NATIONAL SURVEY OF STUDENT ENGAGEMENT. Center for Post Secondary Research Indiana University School of Education, 2017. Disponível em: <http://nsse.indiana.edu/> Acesso: em 23 de junho de 2018.

OECD. The future of education and skills Education 2030, 2018. Disponível em: <https://www.oecd.org/education/2030/E2030\%20Position\%20Paper\%20(05.04.2018).pdf>. Acesso em: 03 de junho de 2018.

OECD. Education Policy outlook 2018: Putting Student learning at the Centre. OECD, Publishing, Paris, 2018. Disponível em: <https://www.oecd-ilibrary.org/education/books >. Acesso em: 16 de julho de 2018.

PARTNERSHIP FOR 21ST CENTURY SKILLS. 21st Century Skills, Education \& Competitiveness. A Resource and Policy Guide, 2008.

PEREIRA, A.; MENDES, A.; MORGADO, L.; AMANTE, L.; BIDARRA, J. Modelo Pedagógico Virtual da Universidade Aberta. Lisboa: Universidade Aberta, 2007. Disponível em <https://goo.gl/LeQTKX>. Acesso em: 16 de julho de 2018.

SAAVEDRA, A; OPFER, V. Teaching and learning $21^{\text {ST }}$ Century Skills: Lessons from the Learning $\quad 2012 . \quad$ Sciences, Disponível em: <https://www.aare.edu.au/data/publications/2012/Saavedra12.pdf>. Acesso em: 05 de junho de 2018.

SALMON, G. E-tivities: the key to teaching and learning online. Londres: Routledge, 2003.

SILVA, A.; DIANA, J.; SPANHOL, F. Comunidade de Prática na Educação a distância: Um estudo no projeto E-NOVA. 2015. Disponível em: <http://www.abed.org.br/congresso2015/anais/pdf/BD_28.pdf>. Acesso em: 15 de julho de 2018.

SINAY, E.; GRAIKINIS, D. Global Competencies in Deeper Learning Environments Enabled by Pervasive Digital Technologies: Evolving Framework for Theoretical Foundation and Developmental Evaluation. (Research Report No. 17/18-22). Toronto, Ontario, Canada: Toronto District School Board. 2018.

SMITH, K.; SHEPPARD, S.; JOHNSON, D., JOHNSON, T. Pedagogies of Engagement: ClassroomBased Practices. Journal of Engineering Education, 2013, v. 94, n. 1. EUA: Medford, MA. 
TROWLER, V.; TROWLER, P. Student engagement evidence summary. Lancaster: The Higher Education Academy, 2010. Disponível em: <http://eprints.lancs.ac.uk/61680/1/Deliverable_2._Evidence_Summary._Nov_2010.pdf>. Acesso em: 16 set. 2017.

UNESCO. Educação 2030. Incheon Declaration and Framework for Action for the implementation of Sustainable Development Goal 4. 2015. Disponível em: <https://en.unesco.org/education2030-sdg4>. Acesso em: 02 de junho de 2018.

WAGNER T. 7 Survival Skills for 21st Century Students. Disponível em: $<$ http://mylearningspringboard.com/7-survival-skills-for-21st-century-students/>. Acesso em: 27 de abril de 2018.

WEF-WORDL ECONOMIC FORUM. New Vision for Education: Fostering Social and Emotional c Learning through Technology. Cologny/Geneva: World Economic Forum, 2015.

Submetido: 03/12/2018

Aprovado: 19/11/2019 